\title{
Increase in finishers and improvement of performance of masters runners in the Marathon des Sables
}

This article was published in the following Dove Press journal:

International Journal of General Medicine

4 June 2013

Number of times this article has been viewed

\author{
Saskia Carolin Jampen' \\ Beat Knechtle ${ }^{1,2}$ \\ Christoph Alexander Rüst ${ }^{1}$ \\ Romuald Lepers ${ }^{3}$ \\ Thomas Rosemann' \\ 'Institute of General Practice and \\ for Health Services Research, \\ University of Zurich, Zurich, \\ Switzerland; ${ }^{2}$ Gesundheitszentrum \\ St Gallen, St Gallen, Switzerland; \\ ${ }^{3}$ INSERM UI093, Faculty of Sport \\ Sciences, University of Burgundy, \\ Dijon, France
}

Aim: The aim of the study was to examine finisher and performance trends of ultrarunners in the Marathon des Sables, the world's largest multistage ultramarathon.

Methods: The age and running speed was analyzed for 6945 finishes of 909 women and 6036 men between 2003 and 2012 at the Marathon des Sables covering about $240 \mathrm{~km}$ in the Moroccan desert.

Results: The number of finishes increased significantly for both women and men from 2003-2012. The annual number of finishes increased in age groups: $30-34$ years $\left(\mathrm{r}^{2}=0.50\right.$; $P=0.021), 45-49$ years $\left(r^{2}=0.81 ; P=0.0004\right)$, and $50-54$ years $\left(r^{2}=0.46 ; P=0.029\right)$ for women and in all age groups older than 35 years for men $\left(35-39\right.$ years: $\mathrm{r}^{2}=0.64, P=0.0054$; 40-44 years: $\mathrm{r}^{2}=0.67, P=0.0036 ; 45-49$ years: $\mathrm{r}^{2}=0.77, P=0.0007 ; 50-54$ years: $\mathrm{r}^{2}=0.72$, $P=0.0018$; 55-59 years: $\mathrm{r}^{2}=0.42, P=0.041$; and 60-64 years: $\left.\mathrm{r}^{2}=0.67, P=0.0038\right)$. The fastest running speed was achieved by runners in the age group of 35-39 years for both sexes. The mean age of overall finishers was $41.0 \pm 9.1$ years for women and $41.3 \pm 9.5$ years for men. For men, running speed improved for athletes in the age group of 35-39 years $\left(\mathrm{r}^{2}=0.44\right.$ $P=0.036)$ and of $40-44$ years $\left(r^{2}=0.51 ; P=0.019\right)$, while it decreased for athletes in the age group of $30-34$ years $\left(r^{2}=0.66, P=0.0039\right)$. For women, running speed remained stable during the study period for athletes in all age groups.

Conclusion: These data suggest that the number of finishers of masters runners older than 40 years increased for both sexes at the Marathon des Sables, as has been previously observed for single-stage ultramarathons. In contrast to women, men aged 35 to 44 years improved running speed during the study period. Future studies are needed to investigate the reasons for the growing numbers of masters athletes in endurance sports and their improvement in performance.

Keywords: age group, athlete, ultraendurance, running speed

\section{Introduction}

Any running event over a distance longer than the classic marathon distance of 42.195 kilometers is defined as an ultramarathon. ${ }^{1}$ Ultramarathon running has become increasingly popular with a growing number of participants since the late $1980 \mathrm{~s}^{2-4}$ Several studies investigated the influence on the performance of ultramarathon runners of different aspects, such as anthropometry,,${ }^{5-7}$ training characteristics, ${ }^{8,9}$ sex, ${ }^{10}$ and age. ${ }^{4}$ Regarding age as a limiting variable for endurance performance, an increased number of participating masters athletes (age $>40$ years) in marathons ${ }^{11,12}$ and ultramarathons ${ }^{2-4}$ has been reported. In the Western States 100-Mile Endurance Run, the participation of masters runners increased between 1974 and 2007, and the mean age of male finishers increased from 41 to $45-47$ years over this period. ${ }^{2}$
Correspondence: Beat Knechtle Facharzt FMH für Allgemeinmedizin, Gesundheitszentrum St Gallen, Vadianstrasse 26, 900I St Gallen, Switzerland

$\mathrm{Tel}+4 \mid$ I 07| 2268282

Fax $+4|07| 2268272$

Email beat.knechtle@hispeed.ch 
Considering performance and age, a slow decline in senior athletes' performance from the age of 50 years and older was detected, and from the age of 75 years, a dramatic decline was demonstrated for track and field events in the National Senior Olympic Games held in 2001. ${ }^{13}$ The age-related decline in running performance correlated with changes of physiological and morphological characteristics with increasing age. ${ }^{14,15}$ Nevertheless, regarding endurance events, in general Masters athletes improved both their endurance and their ultraendurance performance over time in the New York City Marathon ${ }^{12}$ and in the Hawaiian Ironman Triathlon. ${ }^{16}$ Individual athletes improved their performance and the cohort of the Masters athletes' section recorded faster times. This could be due to individual performance improvements, or more likely, to the increasing popularity of running and the events in question, raising the quality of the field where faster individuals are substituting the slower individuals.

An influence of age on running times has also been demonstrated for both sexes in ultramarathons. ${ }^{4}$ Due to the increased number of participating masters athletes in the Western States 100-Mile Endurance Run, the age of the top performers increased for both sexes over time. ${ }^{2}$ Men achieved their fastest running times at the age of 30-49 years. ${ }^{2}$ In the Swiss Alpine Marathon, a $78 \mathrm{~km}$ mountain ultramarathon held in Davos, Switzerland, an increased age for the fastest running times for both sexes was found. ${ }^{17}$ From 1998 to 2011, the age for the fastest running times increased for men from 34 to 38 years and for women from 32 to 39 years. ${ }^{17}$

The reported data about finisher rates and performance trends of masters athletes refer predominantly to single-stage endurance and ultraendurance events with a nonstop racing time. ${ }^{11,12,16,17}$ The requirements of the athletes in multistage races are different, particularly regarding the total length of the race and that the time available for recovery is only overnight. A few studies investigated the age-related finisher rates and performance trends in multistage races, such as the Marathon des Sables, a multistage ultramarathon over a distance of about $240 \mathrm{~km}$ through the Moroccan desert. ${ }^{18} \mathrm{Abou}$ Shoak et al investigated finisher rates and performance trends in multistage ultramarathons held between 1992 and 2010 around the world. ${ }^{19}$ They found that the Marathon des Sables attracted the most multistage ultramarathoners worldwide. There has been one study investigating the finisher rates and performance trends at the Marathon des Sables focusing on nationality and sex. ${ }^{20}$ Knoth et al reported that the number of finishes increased for both sexes over time and that most participants originated from Europe. ${ }^{20}$ Men were faster than women with a higher sex difference compared to results from single-stage endurance races. ${ }^{20}$ It is of interest whether the different requirements of multistage compared with singlestage endurance races affect not only the sex-related, but also the age-related performance trends.

The aim of the present study is to investigate finisher rates and performance trends of runners in different age groups in the multistage ultramarathon Marathon des Sables between 2003 and 2012. Regarding existing literature about singlestage ultramarathons, we hypothesized an increase in the number of finishes and an improvement in the performance of masters runners, also in the world's largest multistage ultramarathon.

\section{Materials and methods}

All finishes in the Marathon des Sables between 2003 and 2012 were included in an analysis of age, sex, and running speed. The data set for this study was obtained from the website of the race. ${ }^{18}$ Data before 2003 were not available. All procedures used in the study met the ethical standards of the Swiss Academy of Medical Sciences ${ }^{21}$ and were approved by the Institutional Review Board of Kanton St Gallen, Switzerland, with a waiver of the requirement for informed consent of the participants, given the fact that the study involved the analysis of publicly available data.

\section{The race}

The Marathon des Sables is an annually held multistage ultramarathon over a distance of about $240 \mathrm{~km}$ through the Moroccan desert. ${ }^{18}$ The number, lengths, and route of the stages have changed every year since the first event in 1986. During the whole competition, the participants have to carry their own equipment, including food and sleeping gear except for water, which is restricted by the organization dependent on the stage distance. ${ }^{18}$ The minimum weight for the equipment is $6.5 \mathrm{~kg}$, and the maximum weight is $15 \mathrm{~kg}$, not including water. The athletes have to carry food containing a minimum of 2000 calories per day. During the race, the mean daytime temperature is $30^{\circ} \mathrm{C}$, and at night, it is $14^{\circ} \mathrm{C} .{ }^{18}$ The minimum age for participation is 18 years. To participate, the competitors must hold a medical certificate including a resting electrocardiogram, obtained not more than 30 days before the start of the race. ${ }^{18}$

\section{Data analysis}

Due to the changing number of stages and the changes in stage length, running speed was calculated over the whole competition to determine the performance of the athletes. For the analysis of the change in running speed in both 
sexes and the change in sex difference across years, the results of the annual top 25 female and male finishers were pooled and analyzed. The top 25 finishers were chosen to have study groups that are large enough to find reliable results. For the analysis of the age-related finisher and performance trends, the annual performance of the top five female and male finishers were pooled and analyzed. An additional inclusion criterion was at least five finishes in at least 9 out of the 10 years. The age group had to have at least five representatives in at least 9 out of 10 years with possibly different individuals. The analysis was not following individuals through time, but following trends in the cohorts potentially with different individuals each year. For women, all age groups between $25-29$ years and $50-54$ years and for men all age groups between 18-24 years and 60-64 years fulfilled the inclusion criteria. To examine the age-related trends, the finishes were categorized in age groups 18-24, 25-29, 30-34, 35-39, 40-44, 45-49, 50-54, 55-59, 60-64, $65-69,70-74$, and $75-79$ years.

\section{Statistical analysis}

To increase the reliability of data analysis, each data set was tested for normal distribution as well as for homogeneity of variances in advance of statistical analyses. Normal distribution was tested using a D'Agostino-Pearson omnibus normality test and homogeneity of variances was tested using a Levene's test in the case of two groups and with a Bartlett's test in the case of more than two groups. To test for significant changes in the development of a variable across the years, linear regression was used. A Student's $t$-test was performed in the case of two groups, to test for differences between the numbers of women and men, the age of all female and male participants, and between the age of the top 25 women and men, per year. A one-way analysis of variance with subsequent Tukey-Kramer post hoc analysis was performed in the case of more than two groups to test for differences between the numbers of participants and the performance in age groups. Statistical analyses were performed using IBM Statistical Package for the Social Sciences Statistics (Version 19, IBM SPSS, Chicago, IL, USA) and GraphPad Prism (Version 5, GraphPad Software, Inc, La Jolla, CA, USA). Significance was accepted at $P<0.05$ (two-sided for $t$-tests). Data in the text are given as mean \pm standard deviation.

\section{Results \\ Overall finisher trends}

Data from 6945 finishes, including 909 women and 6036 men, have been analyzed from the Marathon des
Sables between 2003 and 2012. The number of finishes increased from 37 (2003) to 107 (2012) for women and from 272 (2003) to 687 (2012) for men. Men showed, with a mean number of $603.6 \pm 146.2$ finishes, a higher number of finishes than women, with a mean number of $90.9 \pm 26.7$ finishes $(P<0.0001)$. During the study period, the mean percentage of female finishers was $13.0 \% \pm 1.2 \%$. Both women and men showed an increase in the number of finishes (Figure 1).

\section{Finisher trends of the different age groups}

For both sexes, the age group 40-44 years showed the greatest number of finishes during the study period (Figure 2). Regarding the number of finishes per age group, an increased number of finishers of masters runners was recorded for both sexes (Figure 3). The annual number of female finishers increased in age groups 30-34, 45-49, and 50-54 years (Table 1). In men, the annual number of finishers increased in age groups $35-39,40-44,45-49,50-54,55-59$, and 60-64 years (Table 1).

\section{Age trends of the finishers}

Over time, the mean age remained unchanged in both sexes (Figure 4). The mean age of overall finishers was $41.0 \pm 9.1$ years for women and $41.3 \pm 9.5$ years for men. There was no difference in the overall mean age between women and men $(P>0.05)$. Regarding the annual overall finishers, men (38.5 \pm 7.1 years) were significantly younger than women (39.9 \pm 7.5 years; $P=0.005$ ). The annual top 25 men showed an increase in age $\left(\mathrm{r}^{2}=0.66 ; P=0.0042\right)$, whereas the mean age of the annual top 25 women remained unchanged (Figure 5).

\section{Changes in running speed for different age groups}

Figure 6 presents the changes in running speed for female and male runners over the years from 2003-2012. An increase in running speed could not be observed in any age group for females (Table 2). Regarding the annual top five female finishers in each age group, runners in the 25-29 years age group had a mean speed of $5.3 \pm 0.7 \mathrm{~km}$ per hour slower $(P<0.05)$ than runners in all other age groups, except for the top five female finishers in the 50-54 year old age group with a mean running speed of $5.9 \pm 0.6 \mathrm{~km}$ per hour. The runners in the 35-39 years age group with a mean speed of $7.3 \pm 0.8 \mathrm{~km}$ per hour were significantly faster $(P<0.05)$ than runners in the $45-49$ years and 50-54 years age groups. In women, the top five finishers in each age group did not 


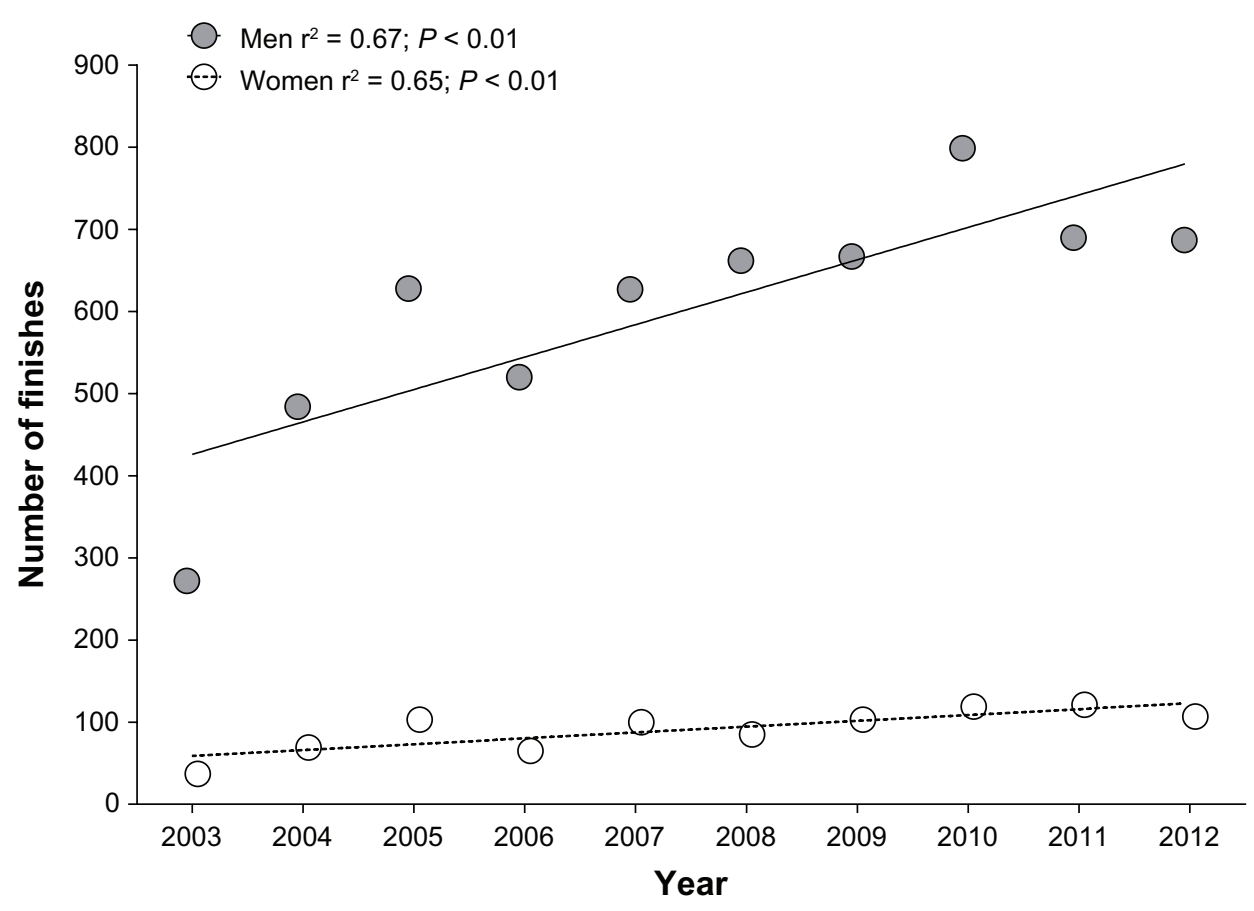

Figure I Changes in the number of male and female finishers across the years.

reach a significantly faster running speed than the other age groups. There was no improvement in the running speed within the different female age groups over the observed time period.

Regarding the annual top five male finishers in each age group, runners in the age group of 18-24 years had a mean speed of $6.6 \pm 0.7 \mathrm{~km}$ per hour significantly slower $(P<0.05)$ than runners in the other age groups, except for the top five male finishers in the age groups of 55-59 and 60-64 years. Finishers in the age group of 30-34 years became slower during the study period and those in the age group of 35-39 and 40-44 years became

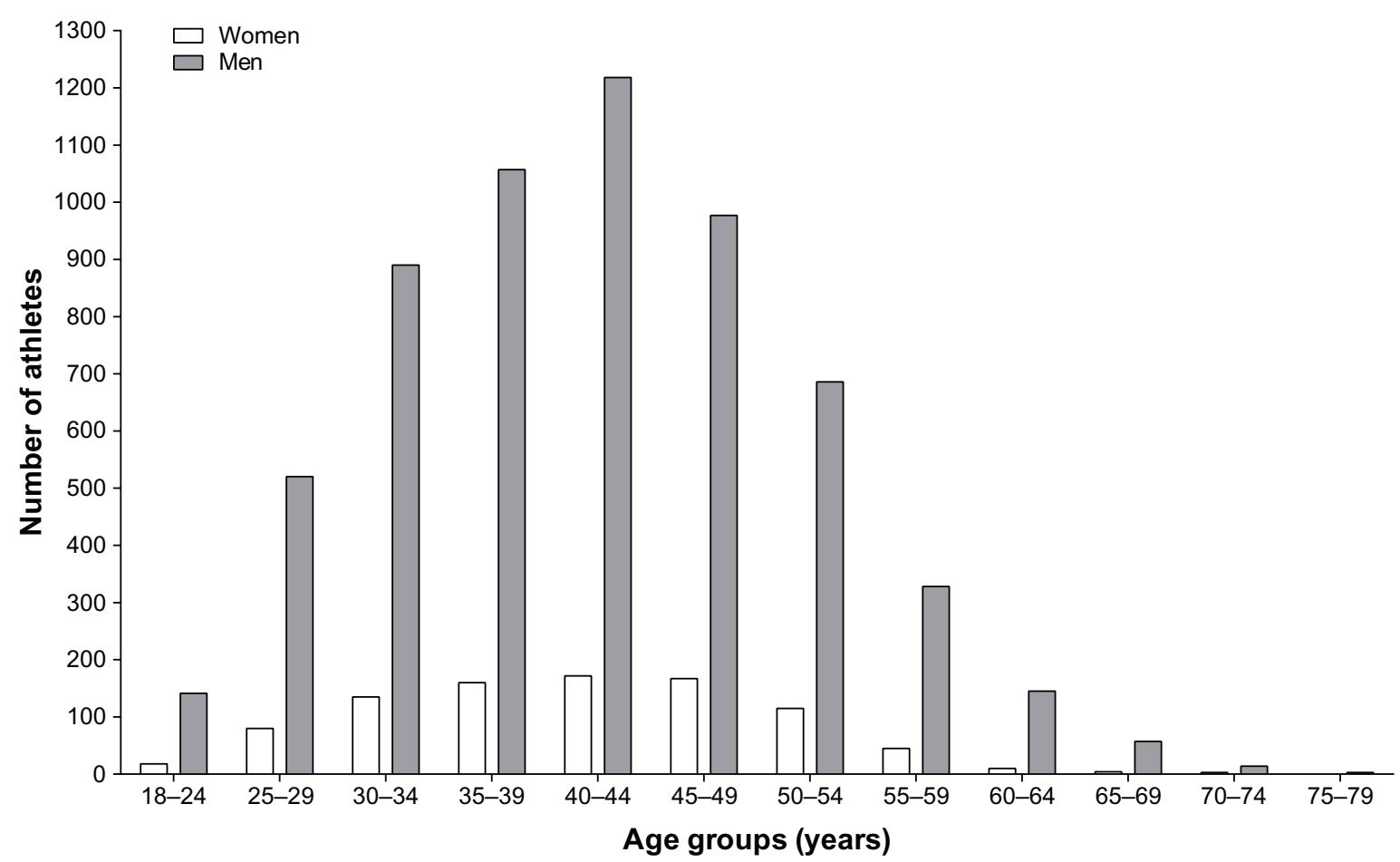

Figure 2 Total numbers of male and female finishers per age group during the investigated 10 -year period. 
A

Women

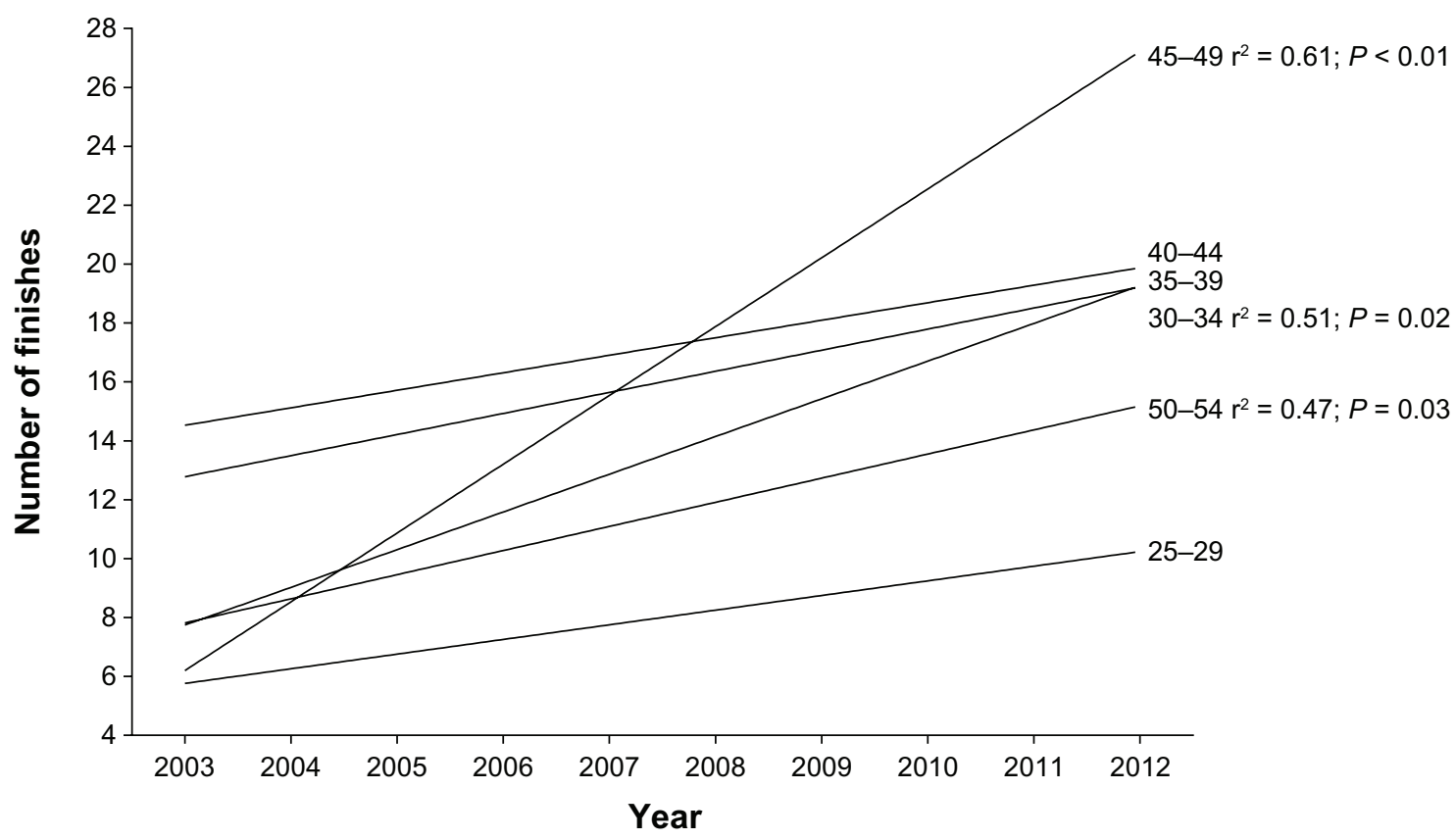

B Men

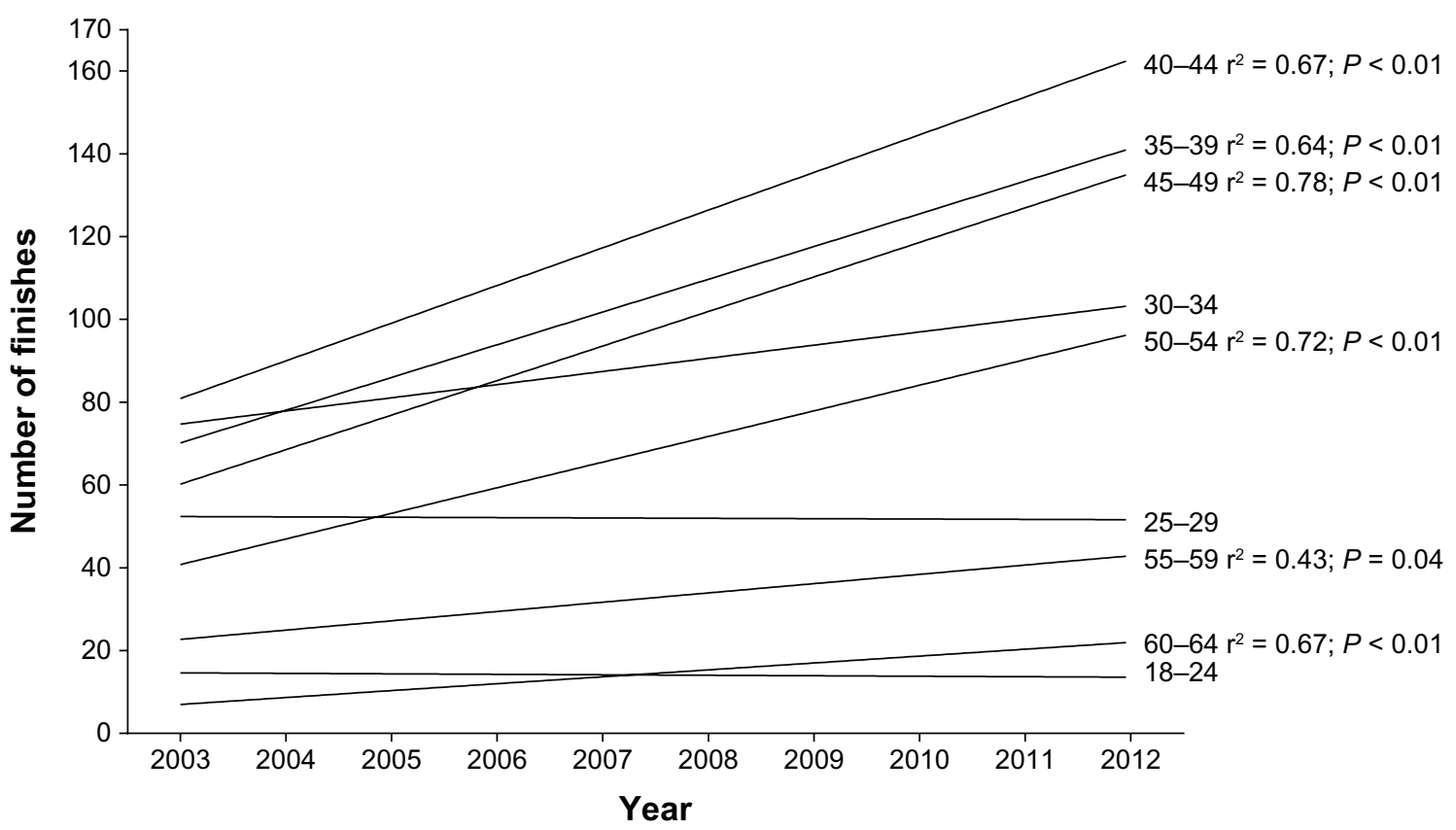

Figure 3 Change in the number of finishes per age group during the study period for women $(\mathbf{A})$ and men $(\mathbf{B})$.

Note: $R^{2}$ and $P$-value of linear regression are given in case of a significant change.

faster during the observed 10-year period (Table 2). Again, no single age group of the annual top five male finishers reached a significantly faster running speed than the others.

\section{Age of fastest running speed}

Regarding the top 25 male and female finishers, for both sexes, the fastest running speed was reached by athletes in age group 35-39 years for women with a mean running speed of $7.4 \pm 0.9 \mathrm{~km}$ per hour and for men with a mean running speed of $10.7 \pm 1.0 \mathrm{~km}$ per hour. In women, the age group with the fastest running speed was not significantly different from that of the 40-44 year old age group with a mean running speed of $7.0 \pm 0.8 \mathrm{~km}$ per hour. In men, the fastest running speed was not significantly different from that of the 30-34 year old age group with a mean running speed 
Table I Change in the number of female and male finishers per age group

\begin{tabular}{llll}
\hline Sex & Age group & $\boldsymbol{r}^{2}$ & $\boldsymbol{P}$ \\
\hline Female & $25-29$ & 0.18 & 0.21 \\
& $30-34$ & 0.50 & 0.021 \\
& $35-39$ & 0.27 & 0.11 \\
& $40-44$ & 0.06 & 0.48 \\
& $45-49$ & 0.81 & 0.0004 \\
Male & $50-54$ & 0.46 & 0.029 \\
& $18-24$ & 0.004 & 0.85 \\
& $25-29$ & 0.0002 & 0.96 \\
& $30-34$ & 0.21 & 0.18 \\
& $35-39$ & 0.64 & 0.0054 \\
& $40-44$ & 0.67 & 0.0036 \\
& $45-49$ & 0.77 & 0.0007 \\
& $50-54$ & 0.72 & 0.0018 \\
& $55-59$ & 0.42 & 0.041 \\
& $64-64$ & 0.67 & 0.0038 \\
\hline
\end{tabular}

of $10.6 \pm 1.3 \mathrm{~km}$ per hour, or from that of the $40-44$ year-oldage group with a mean running speed of $10.6 \pm 0.8 \mathrm{~km}$ per hour (Figure 7).

\section{Discussion}

The aim of this study was to investigate finisher rates and performance trends of runners in different age groups competing in the multistage ultramarathon Marathon des Sables between 2003 and 2012. Based upon existing literature we hypothesized that there would be an increase in finishers and an improvement in the performance of masters runners over this time period. The main findings were: (1) an increase in finishers over the studied period for both sexes; (2) an increase in the number of finishers for masters runners ( $\geq 40$ years) for both sexes during the study period; (3) an improvement in running speed for men in age group 35-44 years; and (4) the fastest running speed was achieved at the age of 35-44 years for women and 30-44 years for men.

\section{Growing number of participants and masters runners}

The first important finding was an increased number of finishers for both women and men. Within the investigated 10 -year period the number of finishers increased by $289 \%$ for women and by $252 \%$ for men, whereas the mean number of male finishers was higher than that of the females. A growing number of participants in ultramarathon running over the years has been previously described for single-stage endurance events in the Western States 100-Mile Endurance Run in the USA ${ }^{2}$ and in the $100 \mathrm{~km}$ Lauf Biel in Switzerland. ${ }^{4}$ Apart from these trends reported for single races, the number of participants increased in longer ultramarathons, such as the Badwater Ultramarathon and the Spartathlon Ultra Race, ${ }^{22,23}$ and in time-limited races, such as 24 -hour ultramarathons. $^{24}$

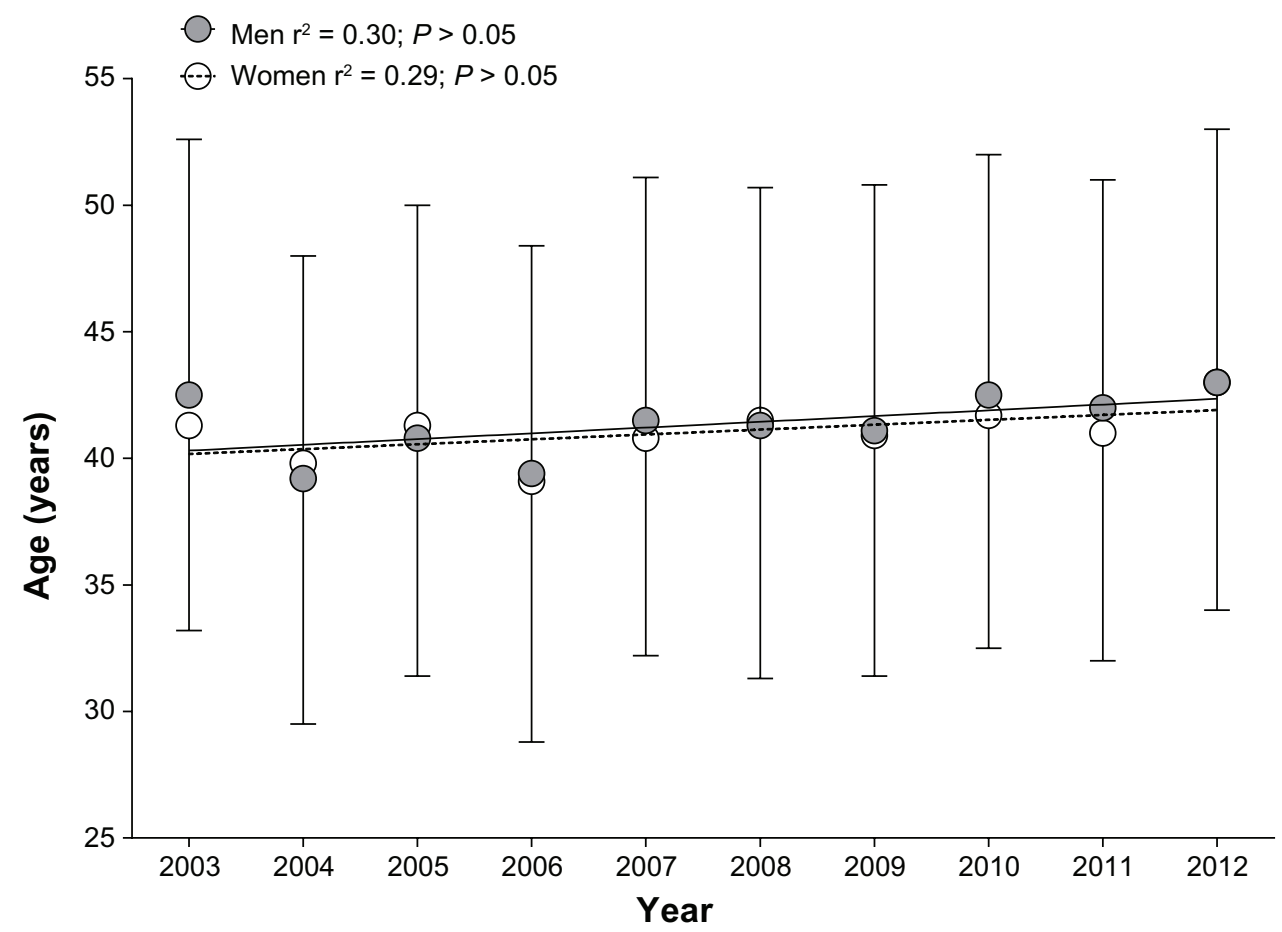

Figure 4 Changes in the mean age of all male and female finishers during the study period. 


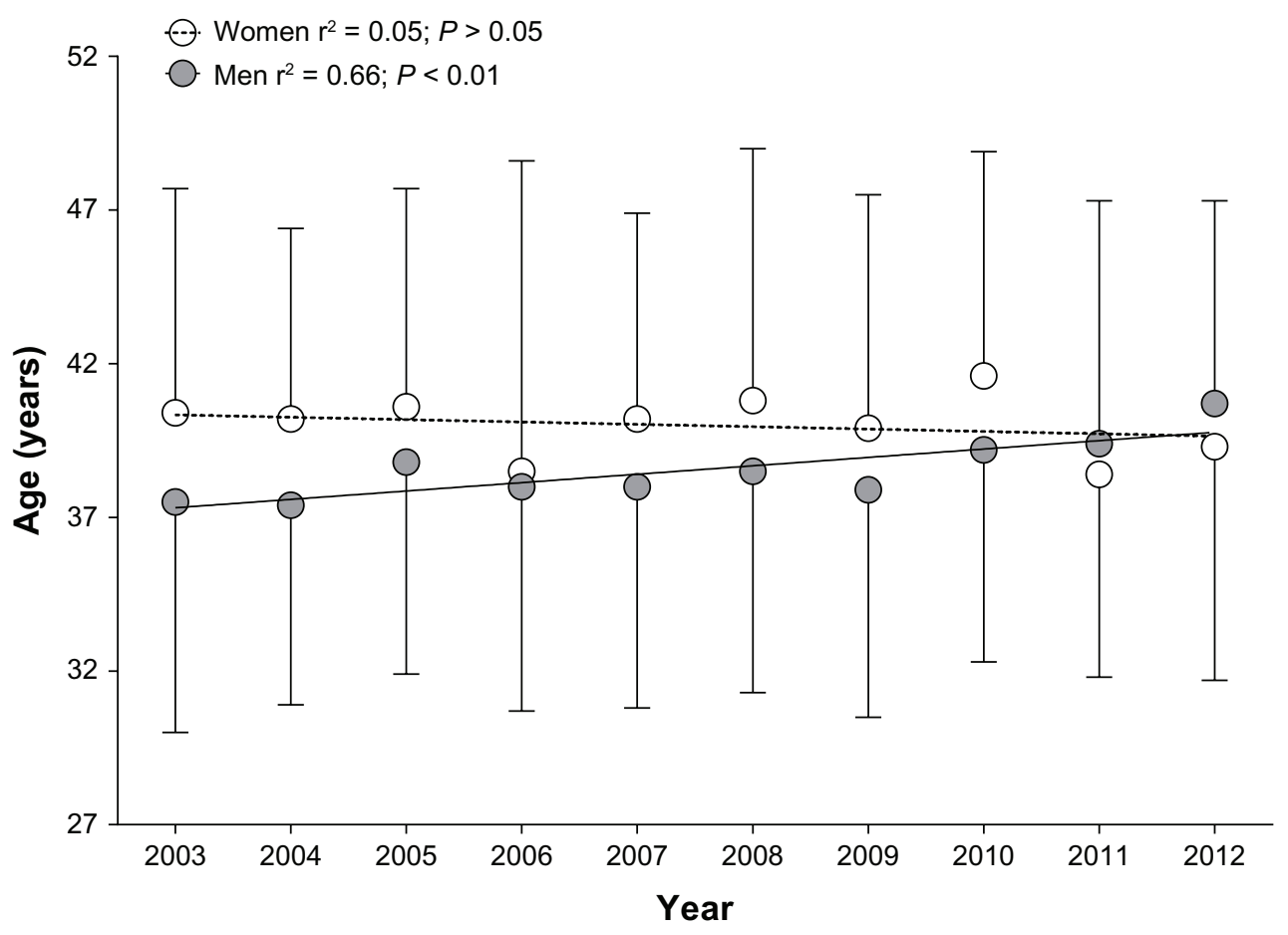

Figure $\mathbf{5}$ Changes in the mean age of the annual top 25 male and female finishers during the study period.

The increase in participants in the Marathon des Sables might also be due the showcase of the race in the media. The Marathon des Sables is ranked by the Discovery Channel as the "toughest footrace on earth." 25 Another website ranks the Marathon des Sables at fourth position behind the Yukon Arctic Ultra, Badwater Ultramarathon, and Antarctica Marathon. ${ }^{26}$ Several websites that report up to date information on ultramarathon running and race reports. ${ }^{27-29}$ Another potential explanation for the increase in participants could be due to the increase in the general population over time. Knoth et al showed that most of the participants in the Marathon des Sables originated from European countries, such as France and the UK. ${ }^{20}$ The general population increase was important to the results, as was the economic background of the Marathon des Sables' participants; the entry fee is very high. ${ }^{20}$

The race seemed to have enjoyed an above-trend participation rate in 2005 and 2010. These milestone years could explain an increase in participation most probably due to an increased presence in mass media, such as Eurosport ${ }^{30}$ or YouTube. ${ }^{31}$ The below-trend decline in 2006 and 2011 - and to some extent also in 2012 might be explained by the fact that potential racers were looking for new challenges. These athletes may compete in other races or other challenges, such as the Yukon Arctic Ultra, ${ }^{32}$ the Jungle Ultra Marathon, ${ }^{33}$ the Badwater
Ultramarathon, ${ }^{22,23}$ the Iditarod Trail International, ${ }^{34}$ or The Barkley Marathons. ${ }^{35}$

The male/female ratio of the number of finishers in endurance running events with a lower number of female finishers has been previously reported for the New York City Marathon. ${ }^{12}$ This phenomenon might be caused by the fact that women started participating in ultramarathons later than men did, showing an increase in the number of finishers in recent years. ${ }^{2}$ Evolutionary psychology could be another explanation for the male dominance in sports. ${ }^{36}$ A sex difference in enduring competitiveness has already been investigated, in which it was postulated that men have a greater training motivation. ${ }^{37}$

Women significantly increased their number of finishers in the Marathon des Sables in age groups 30-34 and 45-54 years over the investigated time period. Men increased the number of finishers in all age groups from 35 to 64 years. For women, similar results were reported in a short distance triathlon, the Zürich Triathlon, with an increased number of finishers of female triathletes aged from 40 to 54 years. ${ }^{38}$ Our findings regarding this increased number of finishers for masters runners and the increased age of the top 25 male finishers during the study period corresponds to previous findings for single-stage events. At the Western States 100-Mile Endurance Run, an increased number of finishers of masters runners over the years and 
A

Women

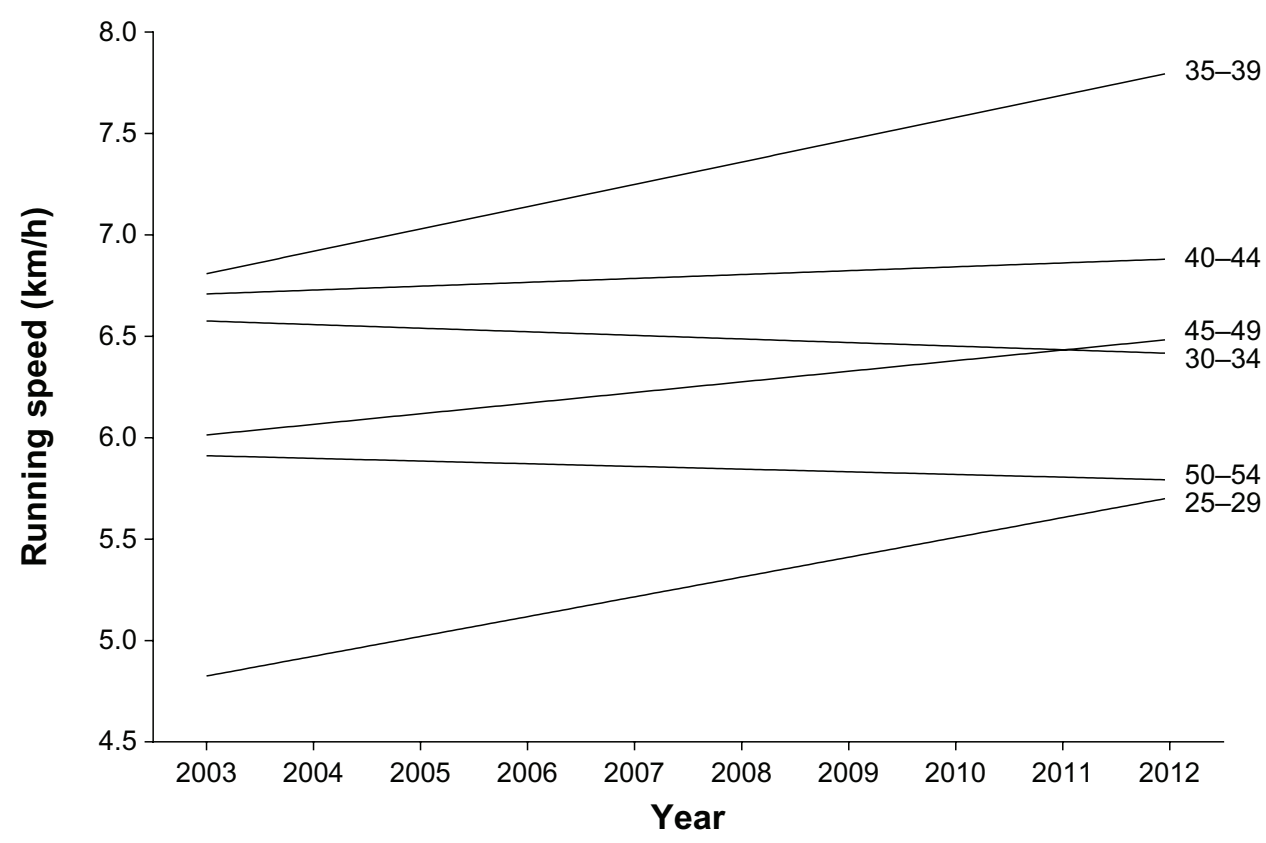

B

Men

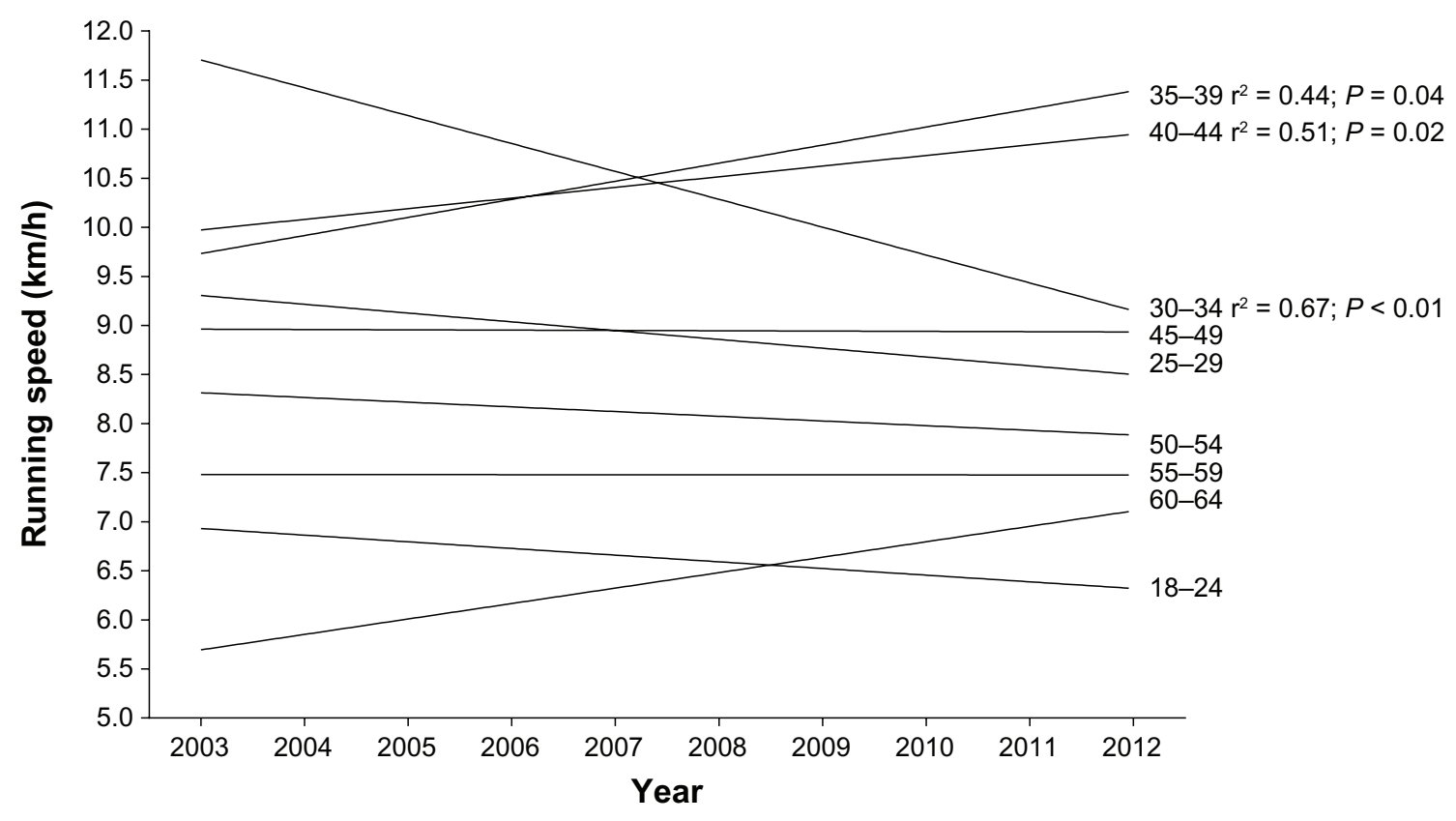

Figure 6 Changes in running speed of the top five athletes per age group for women (A) and for men (B).

Note: $R^{2}$ and $P$-value of linear regression are given in case of a significant change during the study period.

increasing ages of the top performers for both sexes has been shown. ${ }^{2}$ Similar results were reported for the New York City Marathon. ${ }^{12}$ This increased number of masters finishers in ultramarathons could be explained by the increasing life expectancy ${ }^{39}$ and the growing proportion of elderly people in our society, ${ }^{40}$ but further studies are needed.

\section{Improved running speed of male masters runners}

Male masters runners in the age group 40-44 years improved running speed over the study period in the Marathon des Sables. This improvement of masters athletes' performance is in accordance with reported data for singlestage endurance events. Masters athletes also improved 
Table 2 Change in running speed of female and male finishers per age group

\begin{tabular}{llll}
\hline Sex & Age group & $\boldsymbol{r}^{2}$ & $\boldsymbol{P}$ \\
\hline Female & $25-29$ & 0.20 & 0.18 \\
& $30-34$ & 0.0048 & 0.84 \\
& $35-39$ & 0.15 & 0.25 \\
& $40-44$ & 0.015 & 0.77 \\
& $45-49$ & 0.10 & 0.36 \\
Male & $50-54$ & 0.0046 & 0.85 \\
& $18-24$ & 0.086 & 0.41 \\
& $25-29$ & 0.14 & 0.27 \\
& $30-34$ & 0.66 & 0.0039 \\
& $35-39$ & 0.44 & 0.036 \\
& $40-44$ & 0.51 & 0.019 \\
& $45-49$ & 0.00065 & 0.94 \\
& $50-54$ & 0.13 & 0.28 \\
& $55-59$ & 0.0000039 & 0.98 \\
& $60-64$ & 0.23 & 0.15 \\
\hline
\end{tabular}

performance over the years in the New York City Marathon ${ }^{12}$ and in the Hawaiian Ironman Triathlon. ${ }^{16}$ A possible reason for this improved performance of masters runners could be their greater competition experience with ultraendurance events. ${ }^{9}$ Similarly, for long-distance inline skaters, it has been shown that previous experience can be used as an important predictor for race performance. ${ }^{41}$ Masters athletes may have better opportunities to recover from races since they compete less than younger athletes. In addition, the higher participation of masters athletes over the years increases the opportunity for improved performance. Further studies are needed to investigate the reasons for the improved performance of masters athletes over the years.

In the Marathon des Sables, only male masters athletes in the age group of 40-44 years improved their performance, while the performance of the older masters athletes in the age groups between 45 and 64 years remained stable. Changes of body composition with aging have been previously described, such as a decreased skeletal muscle mass, ${ }^{42}$ a decreased fatfree mass, a decreased appendicular skeletal muscle mass, a decreased body cell mass, and a decreased total body potassium with increasing age. ${ }^{43}$ These age-related changes are described to be associated with decreased performance where a positive correlation between body fat and race times in masters half-marathoners ${ }^{44}$ and between body mass and race performance in ultraendurance runners have been shown. ${ }^{6}$ In addition, Tanaka and Seals reported on the decreased $\mathrm{VO}_{2}$ max with aging and on the association with

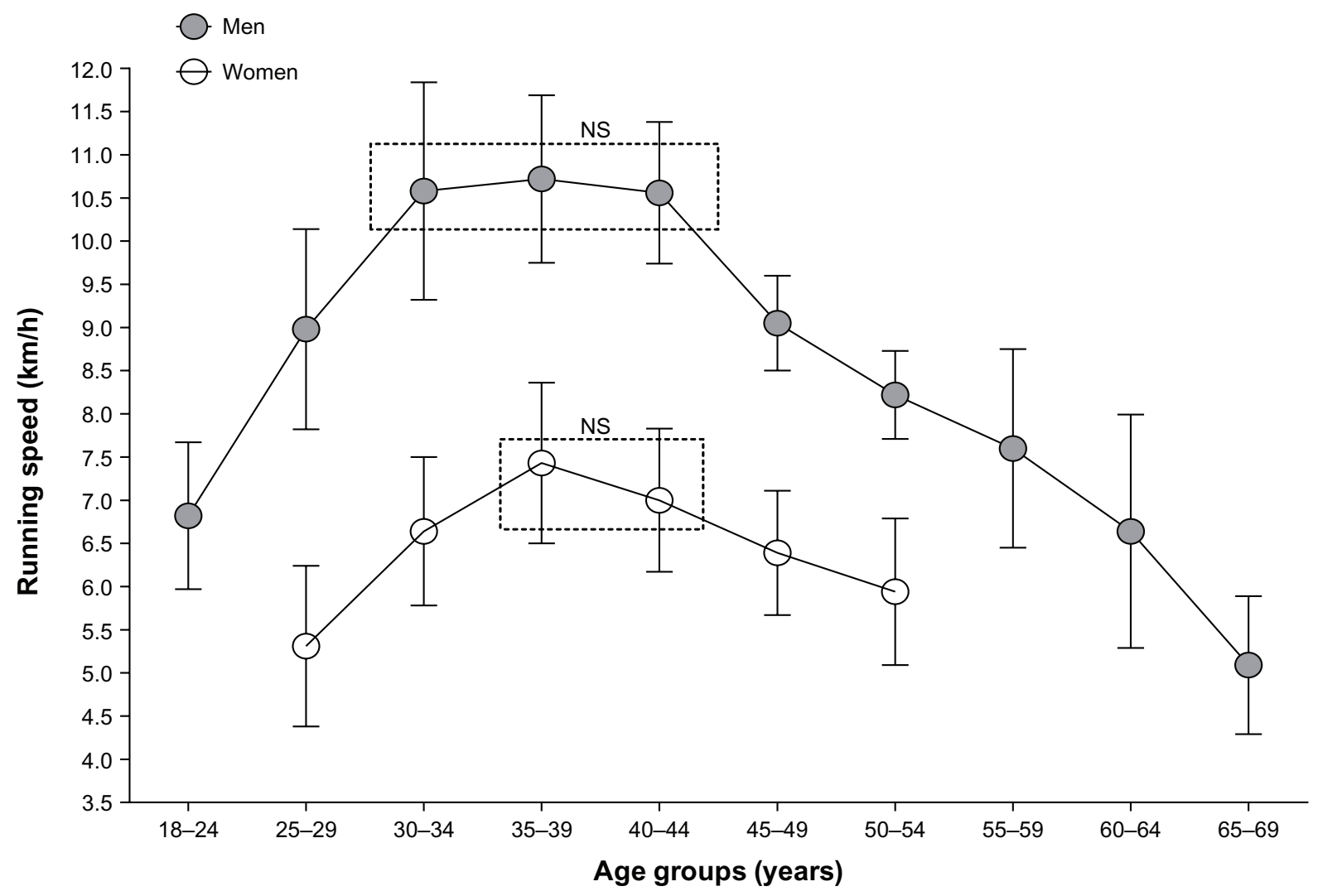

Figure 7 Mean $( \pm S D)$ performance of the best 25 male and female finishers per age group during the 2003-2012 period.

Note: NS indicates age groups that were not significantly different from each other.

Abbreviations: SD, standard deviation; NS, not significant. 
a decline in endurance running performance. ${ }^{45}$ The impact of these age-related physiological changes on masters athletes' performance might be greater in the multistage Marathon des Sables when compared with other singlestage ultramarathons, due to the higher requirements on the athletes. Accordingly, a correlation between marathon running performance and air temperature has been shown where running speed decreased with increasing ambient temperature. ${ }^{46}$ Reasons why athletes aged older than 45 years were unable to improve their performance could include the greater total length of the race and the reduced opportunities for recovery time during the race. In addition, an association between training volume and performance in ultramarathons was described by Knechtle et al. ${ }^{8}$ Another explanation for our finding could be the lower training volumes of masters endurance athletes compared to their younger colleagues. ${ }^{14}$

Only male masters athletes in the Marathon des Sables could improve their performance, while the performance of female masters athletes remained stable. This phenomenon could be explained by sex differences, for example, women having a smaller $\mathrm{VO}_{2} \max ^{47}$ and numerous other sex differences regarding the anatomy, physiology, biomechanics, and psychology, as described by Lynch and Hoch. ${ }^{48}$ In the Marathon des Sables with its multiple stages, the impact of these sex differences on performance could be potentially greater, resulting in only male athletes being able to improve their performance over the study period.

\section{Age of peak performance}

The age range of athletes with the fastest running speed in the Marathon des Sables was 35-44 years for women and 30-44 years for men, similar to those found in other singlestage ultramarathons, such as the $100 \mathrm{~km}$ Lauf Biel, with an age spread of 30-49 years. ${ }^{4}$ In slight contrast, Hoffman and Fogard reported that the mean age of peak performance for $161 \mathrm{~km}$ ultramarathoners was about 45 years. ${ }^{49}$ Due to the higher requirements of the multistage Marathon des Sables, being younger than 45 years could be beneficial for achieving the fastest running times. Accordingly, Graham et al found an increased fatigue and reduced vigor for athletes during a desert ultramarathon. ${ }^{50}$ Due to the age-related decline of $\mathrm{VO}_{2}$ max, which is described to be strongly associated with decreased performance, ${ }^{45}$ being younger than 45 years could also be beneficial for reaching peak performance in the Marathon des Sables. Furthermore, an increase in the body mass index with aging in the general population has been reported..$^{51}$ Another possible explanation for the superiority of the younger athletes regarding the fastest running speed could be the lower body mass index when compared with masters athletes, which has been described to be associated with a faster performance time in ultramarathoners. ${ }^{5}$ An explanation for the finding that athletes older than 30 years reached the fastest running times could be their greater experience with competing in ultraendurance events. ${ }^{9}$ Accordingly, a high training volume is described as being more important for a faster performance than anthropometric variables. $^{8}$

\section{Limitations and implications for future research}

This study is limited due to the inability to include some factors such as anthropometric parameters, ${ }^{5,6,52}$ training characteristics, ${ }^{8,9}$ origin of the athletes, ${ }^{19,20,53,54}$ nutrition, ${ }^{55-57}$ overuse injuries ${ }^{58,59}$ motivation, ${ }^{60}$ heat,${ }^{46,61}$ and previous experience in ultraendurance events. ${ }^{9,41}$ Also, the effect of meteorological conditions on the running speed could be of interest. ${ }^{46,52,62}$ To increase the validity of the comparison between sex differences, higher numbers of female athletes are needed. More data for further statistical analyses are needed to investigate the influence of environmental conditions on the running speed.

\section{Conclusion}

In the multistage Marathon des Sables, an increase in the annual number of finishes in age groups 30-34 and 45-54 years for women and in all age groups older than 35 years for men was shown. As reported in the current literature for single-stage ultramarathons, the number of finishers of masters runners older than 40 years increased for both sexes and male masters runners improved their running speed. In contrast to women, men aged 35-44 years had improved running speed. Further studies are needed to investigate finisher and performance trends of masters athletes in other multistage ultraendurance sports and to investigate the reasons for the growing number of masters athletes and their improvement in performance.

\section{Disclosure}

The authors declare no conflicts of interest in this work.

\section{References}

1. Godden K. Ultramarathon running resource. [homepage on the Internet]. Buckinghamshire, UK: ULTRAmarathonRunning.com; 2013. Available from: http://www.ultramarathonrunning.com/. Accessed October 22, 2012.

2. Hoffman MD, Wegelin JA. The Western States 100-Mile Endurance Run: participation and performance trends. Med Sci Sports Exerc. 2009; 41(12):2191-2198. 
3. Hoffman MD, Ong JC, Wang G. Historical analysis of participation in $161 \mathrm{~km}$ ultramarathons in North America. Int J Hist Sport. 2010;27(10): 1877-1891.

4. Knechtle B, Rüst CA, Rosemann T, Lepers R. Age-related changes in $100 \mathrm{~km}$ ultramarathon running performance. Age (Dordr). 2012;34(4): 1033-1045.

5. Hoffman MD. Anthropometric characteristics of ultramarathoners. Int J Sports Med. 2008;29(10):808-811.

6. Knechtle B, Duff B, Welzel U, Kohler G. Body mass and circumference of upper arm are associated with race performance in ultraendurance runners in a multistage race - the Isar Run 2006. Res Q Exerc Sport. 2009;80(2):262-268.

7. Rüst CA, Knechtle B, Knechtle P, Rosemann T. Similarities and differences in anthropometry and training between recreational male $100 \mathrm{~km}$ ultramarathoners and marathoners. J Sports Sci. 2012;30(12): 1249-1257.

8. Knechtle B, Wirth A, Knechtle P, Rosemann T. Training volume and personal best time in marathon, not anthropometric parameters, are associated with performance in male $100 \mathrm{~km}$ ultrarunners. J Strength Cond Res. 2010;24(3):604-609.

9. Knechtle B, Knechtle P, Rosemann T, Lepers R. Personal best marathon time and longest training run, not anthropometry, predict performance in recreational 24-hour ultrarunners. J Strength Cond Res. 2011;25(8):2212-2218.

10. Cheuvront SN, Carter R, Deruisseau KC, Moffatt RJ. Running performance differences between men and women: an update. Sports Med. 2005;35(12):1017-1024.

11. Jokl P, Sethi PM, Cooper AJ. Masters' performance in the New York City Marathon 1983-1999. Br J Sports Med. 2004;38(4):408-412.

12. Lepers R, Cattagni T. Do older athletes reach limits in their performance during marathon running? Age (Dordr). 2012;34(3):773-781.

13. Wright VJ, Pericelli BC. Age-related rates of decline in performance among elite senior athletes. Am J Sports Med. 2008;36(3): 443-450.

14. Pollock ML, Mengelkoch KJ, Graves JE, et al. Twenty-year follow-up of aerobic power and body composition of older track athletes. $J$ Appl Physiol. 1997;82(5):1508-1516.

15. Korhonen MT, Mero AA, Alén M, et al. Biomechanical and skeletal muscle determinants of maximum running speed with aging. Med Sci Sports Exerc. 2009;41(4):844-856.

16. Lepers R, Rüst CA, Stapley PJ, Knechtle B. Relative improvements in endurance performance with age: evidence from 25 years of Hawaii Ironman racing. Age (Dordr). Epub February 26, 2012.

17. Eichenberger E, Knechtle B, Rüst CA, Rosemann T, Lepers R. Age and sex interactions in mountain ultramarathon running - the Swiss Alpine Marathon. Open Access J Sports Med. 2012;3:73-80.

18. Sultan Marathon des Sables [homepage on the Internet]. Troyes Cedex, France: Sultan Marathon des Sables. Available from: http://www. darbaround.com/. Accessed March 4, 2012.

19. Abou Shoak M, Knechtle B, Rüst CA, Lepers R, Rosemann T. European dominance in multistage ultramarathons: an analysis of finisher rate and performance trends from 1992 to 2010. Open Access J Sports Med. 2013;4:9-18.

20. Knoth C, Knechtle B, Rüst CA, Rosemann T, Lepers R. Participation and performance trends in multistage ultramarathons - the Marathon des Sables 2003-2012. Extreme Physiology and Medicine. 2012;1:13.

21. The Swiss Academy of Medical Sciences (SAMS). Available from: http://www.samw.ch/en/Ethics/Guidelines/Currently-valid-guidelines. html. Accessed April 7, 2013.

22. Da Fonseca-Engelhardt K, Knechtle B, Rüst CA, Knechtle P, Lepers R, Rosemann T. Participation and performance trends in ultraendurance running races under extreme conditions - Spartathlon versus Badwater. Extreme Physiology and Medicine. In press.

23. Zingg M, Rüst CA, Knechtle B, Rosemann T, Lepers R. Analysis of participation and performance in age group athletes in ultramarathons of more than $200 \mathrm{~km}$ in length. Int J Gen Med. 2013;6: 209-220.
24. Zingg M, Rüst CA, Rosemann T, Lepers R, Knechtle B. Master runners dominate the 24-hour ultramarathons worldwide - a retrospective data analysis from 1998 to 2011. Extreme Physiology and Medicine. In press.

25. The 6 Hardest Races in the World. http://news.discovery.com/adventure/ the-six-hardest-races-in-the-world.htm. Accessed April 7, 2013.

26. Marathon des Sables. [homepage on the Internet]. München, Germany; CHIP Communications GmbH; 2012. Marathon des Sables. Available from: http://www.zehn.de/marathon-des-sables-3261601-4. Accessed April 7, 2013.

27. Adventure runner, making every run an adventure. http://www. adventurerunner.co.uk/running-the-marathon-des-sables/. Accessed April 7, 2013

28. Mencap. [homepage on the Internet]. London, England: 2014 Marathon des Sables; 2012. Available from: http://www.mencap.org.uk/getinvolved/events/2014-marathon-des-sables. Accessed April 7, 2013.

29. Ultrarun. http://ultrarun.com/marathon-des-sables-2014/. Accessed April 7, 2013

30. Marathon des Sables on Eurosport. Eurosport.com. [homepage on the Internet]. France: Marathon des Sables on Eurosport; 2012. Available from: video.eurosport.fr/marathon/marathon-des-sables_vid101226/ video.shtml. 2013. Accessed April 7, 2013.

31. Dicu P/EuroSport. Marathon des Sable; 2012. Available from: http:// www.youtube.com/watch?v=bQ-b4ZkLxIo. Accessed April 7, 2013.

32. Pollhammer Robert. Yukon Arctic Ultra. [homepage on the Internet]. Germany: ArcticUltra.de; 2012. Available from: http://www.arcticultra. de/. Accessed April 7, 2013.

33. Jungle Marathon Ltd. [homepage on the Internet]. London, UK: Jungle Ultra Marathon Ltd; 2012. Available from: http://www.junglemarathon. com. Accessed April 7, 2013.

34. Merchant Bill. What this race is all about. [homepage on the Internet]. Anchorage, AK: Alaska Ultra Sport LLC; 2013. Available from: http:// www.alaskaultrasport.com/alaska_ultra_home_page.html. Accessed April 7, 2013.

35. Mahoney Matt. The Barkley Marathons - 100 Mile Run. [homepage on the Internet]. Available from: http://www.mattmahoney.net/barkley/. Accessed April 7, 2013.

36. Lombardo MP. On the evolution of sport. Evol Psychol. 2012; 10(1):1-28.

37. Deaner RO. Distance running as an ideal domain for showing a sex difference in competitiveness. Arch Sex Behav. 2013;42(3):413-428.

38. Etter F, Knechtle B, Bukowski A, Rüst CA, Rosemann T, Lepers R. Age and gender interactions in short distance triathlon performance. J Sports Sci. Epub January 28, 2013.

39. Faber JF. Life Tables for the United States: 1900-2050. Actuarial study number 87. Baltimore, MD: Social Security Administration; 1982.

40. United Nations. World Population Prospects: The 2004 Revision. New York: United Nations; 2004. United Nations Department of Economic and Social Affairs. Available from: http://www.un.org/esa/population/ publications/WPP2004/2004Highlights_finalrevised.pdf. Accessed March 12, 2013.

41. Knechtle B, Knechtle P, Rüst CA, Rosemann T, Lepers R. Age, training, and previous experience predict race performance in long-distance inline skaters, not anthropometry. Percept Mot Skills. 2012;114(1): 141-156.

42. Shephard RJ. Age and physical work capacity. Exp Aging Res. 1999; 25(4):331-343.

43. Kyle UG, Genton L, Hans D, Karsegard L, Slosman DO, Pichard C. Age-related differences in fat-free mass, skeletal muscle, body cell mass, and fat mass between 18 and 94 years. Eur J Clin Nutr. 2001; 55(8):663-672.

44. Knechtle B, Rüst CA, Knechtle P, Rosemann T. Does muscle mass affect running times in male long-distance master runners? Asian $J$ Sports Med. 2012;3(4):247-256.

45. Tanaka H, Seals DR. Invited review: dynamic exercise performance in master athletes: insight into the effects of primary human aging on physiological functional capacity. J Appl Physiol. 2003;95(5):2152-2162. 
46. El Helou N, Tafflet M, Berthelot $\mathrm{G}$, et al. Impact of environmental parameters on marathon running performance. PLoS One. 2012;7(5): e37407.

47. Sandbakk O, Ettema G, Holmberg HC. Gender differences in endurance performance by elite cross-country skiers are influenced by the contribution from poling. Scand J Med Sci Sports. Epub May 24, 2012.

48. Lynch SL, Hoch AZ. The female runner: Gender specifics. Clin Sports Med. 2010;29:477-498.

49. Hoffman MD, Fogard K. Demographic characteristics of $161 \mathrm{~km}$ ultramarathon runners. Res Sports Med. 2012;20(1):59-69.

50. Graham SM, McKinley M, Chris CC, et al. Injury occurrence and mood states during a desert ultramarathon. Clin J Sport Med. 2012;22(6): 462-466.

51. Guo SS, Zeller Ch, Chumlea WC, Siervogel RM. Aging, body composition, and lifestyle: the Fels Longitudinal Study. Am J Clin Nutr. 1999;70(3):405-411.

52. Abbiss CR, Burnett A, Nosaka K, Green JP, Foster JK, Laursen PB. Effect of hot versus cold climates on power output, muscle activation, and perceived fatigue during a dynamic $100 \mathrm{~km}$ cycling trial. $J$ Sports Sci. 2010;28(2):117-125.

53. Eichenberger E, Knechtle B, Rüst CA, Lepers R, Rosemann T, Onywera VO. The aspect of nationality and performance in a mountain ultramarathon - the Swiss Alpine Marathon. Journal of Human Sport and Exercise. 2012;7(4):748-762.

54. Knechtle B, Rüst CA, Rosemann T. The aspect of nationality in participation and performance in ultramarathon running - a comparison between Badwater and Spartathlon. Open Access Sports Medicine. 2012;1(1):1.
55. Bürge J, Knechtle B, Knechtle P, Gnädinger M, Rüst CA, Rosemann T. Maintained serum sodium in male ultramarathoners - the role of fluid intake, vasopressin, and aldosterone in fluid and electrolyte regulation. Horm Metab Res. 2011;43(9):646-652.

56. Costa RJ, Teixeira A, Rama L, et al. Water and sodium intake habits and status of ultraendurance runners during a multistage ultramarathon conducted in a hot ambient environment: an observational field based study. Nutr J. 2013;12:13.

57. Knechtle B, Knechtle P, Rüst CA, et al. Regulation of electrolyte and fluid metabolism in multistage ultramarathoners. Horm Metab Res. 2012;44(12):919-926.

58. Freund W, Weber F, Billich C, Schuetz UH. The foot in multistage ultramarathon runners: experience in a cohort study of 22 participants of the Trans Europe Footrace Project with mobile MRI. BMJ Open. 2012;2(3):e001118.

59. Lopes AD, Hespanhol Júnior LC, Yeung SS, Costa LO. What are the main running-related musculoskeletal injuries? A systematic review. Sports Med. 2012;42(10):891-905.

60. Krouse RZ, Ransdell LB, Lucas SM, Pritchard ME. Motivation, goal orientation, coaching, and training habits of women ultrarunners. J Strength Cond Res. 2011;25(10):2835-2842.

61. Roth HJ, Leithäuser RM, Doppelmayr H, et al. Cardiospecificity of the 3rd generation cardiac troponin T assay during and after a $216 \mathrm{~km}$ ultraendurance marathon run in Death Valley. Clin Res Cardiol. 2007; 96(6):359-364.

62. Parise CA, Hoffman MD. Influence of temperature and performance level on pacing a $161 \mathrm{~km}$ trail ultramarathon. Int J Sports Physiol Perform. 2011;6(2):243-251.
International Journal of General Medicine

\section{Publish your work in this journal}

The International Journal of General Medicine is an international, peer-reviewed open-access journal that focuses on general and internal medicine, pathogenesis, epidemiology, diagnosis, monitoring and treatment protocols. The journal is characterized by the rapid reporting of reviews, original research and clinical studies across all disease areas.

\section{Dovepress}

A key focus is the elucidation of disease processes and management protocols resulting in improved outcomes for the patient. The manuscript management system is completely online and includes a very quick and fair peer-review system. Visit http://www.dovepress.com/ testimonials.php to read real quotes from published authors. 